QSHC in the digital age

\section{QSHC in the digital age}

\section{Mitchell}

Immediate access to the newest content, personal service, and an online archive with links to over one million articles

A s the nature of publishing has shifted in a digital age, so the role of a publisher has changed from guardian to gateway, and our websites need to facilitate finding content quickly and efficiently. Several new online features make QSHC work for you With greater interaction you can get maximum use with minimal effort.

\section{PUSH AND PULL TECHNOLOGY}

We're all familiar with emails from websites that give you up to date news and offers, trying to pull you to their content. Our sites have the same email features, but we'll only send you things you ask for.

Did you know that each new issue goes online up to 2 weeks before the print issue drops through your door? You can sign up to receive an email telling you when a new issue is ready. If you're searching for past articles you can browse (see below) by topic, by issue, or by date. Why not receive an alert when a new article is added to any of these categories, instead of continuously checking the site? To sign up to these alerting services, go to the home page and follow the "New content alerts" link (fig 1).

You might have heard of RSS (fig 2) if so, you're among only $12 \%$ of web users who have. ${ }^{1}$ RSS-really simple syndication-is like an opt-in email service where you control what gets sent to you. If you see this symbol on a page, right click on it, choose "Save link/ target as", and then paste the link into your feed aggregator. ${ }^{2}$ An aggregator is a piece of software that you download to your desktop and where you arrange all the feeds you choose to save. Essentially, you are creating, all in one place, an entire directory of content from the QSHC website and others that you've selected. If you want to find out more there's an "About RSS" link on the home page (fig 1).

\section{A GATEWAY TO OVER ONE MILLION ARTICLES}

Every article's reference list is a gateway to more valuable research. To facilitate reaching that content, HighWire-who provide the platform that hosts the QSHC website-have developed sophisticated inter-journal linking software. HighWire scans all articles for references or URLs. These are then automatically linked up to the free full text of an article if it is hosted on HighWire, ${ }^{3}$ the citation in CrossRef, ${ }^{4}$ or the abstract on PubMed. ${ }^{5}$ So, by accessing the full text of one article, you are potentially opening up access to a whole series of related research. This is helpfully represented by another feature called a citation map (fig 3) which is available for every article in the box on the right hand side of the article. Each bubble is clickable, opening out a whole new citation map (although the map only shows articles found on HighWire).

\section{Searching and browsing}

Just think: HighWire hosts 926 journals, has four of the top five medical journals and over 1.3 million free full text articles online. That's a lot of linked articles! And that's a lot of material to search through. That's why we've put a quick search box on all of our pages. You can

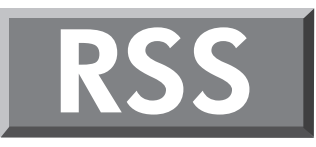

Figure 2 RSS (really simple syndication) pushes content to your desktop. It is set to become a popular method of delivering content.

search by author, keyword, or citation and, if that isn't detailed enough for you, there's an advanced search page where you can refine your searches even further. Of course, you might still be comfortable with the idea of browsing issue by issue, and you can do that on the QSHC archive page.

Our search box is the most highly used feature on the site, and we're proud to make our content as accessible as possible to you, but everyone needs a little help from time to time. That's why we've allowed Google to search the full text of all of our content. Google now sends six times more people to our sites than PubMed.

\section{AT YOUR SERVICE}

Another new feature on our websites allows readers to turn illustrations from our articles into PowerPoint slides with just two clicks of the mouse. It's already proving quite popular with our users, with over 340 images being downloaded from QSHC every month. To use this feature, first navigate to the image that you want within the full text of an article, select the option labelled "View

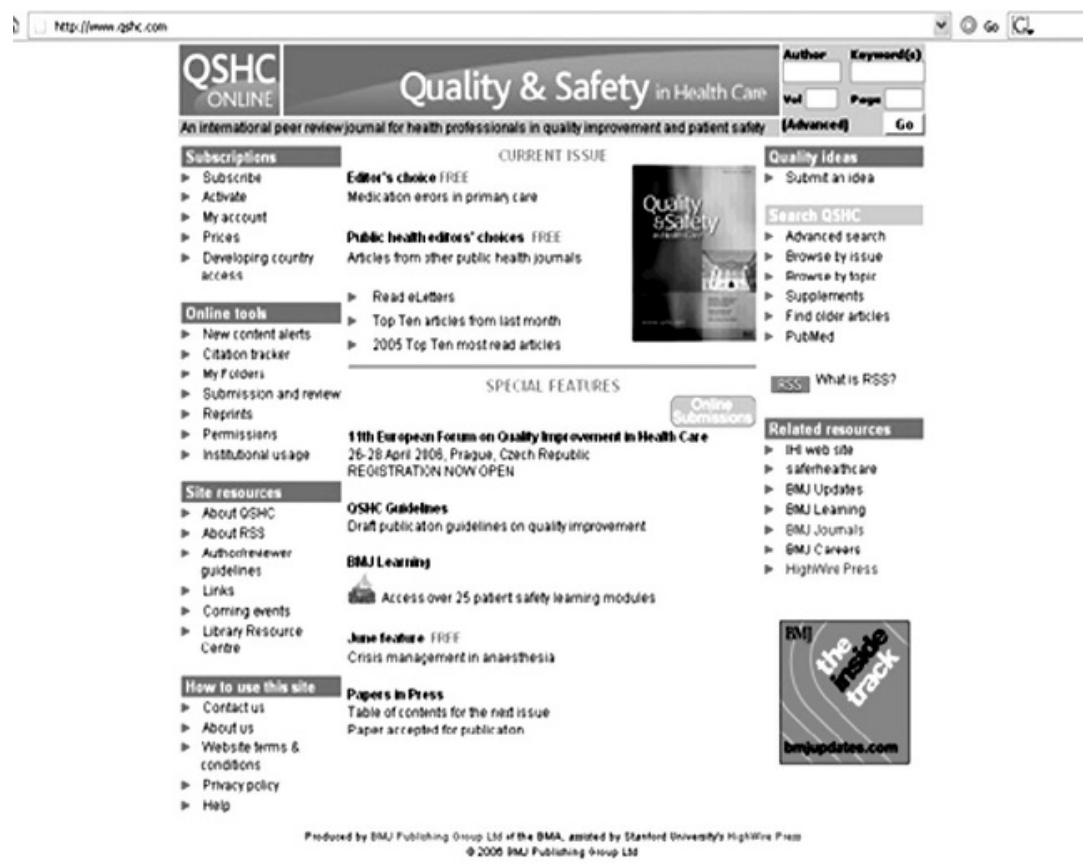

Figure 1 QSHC home page. 


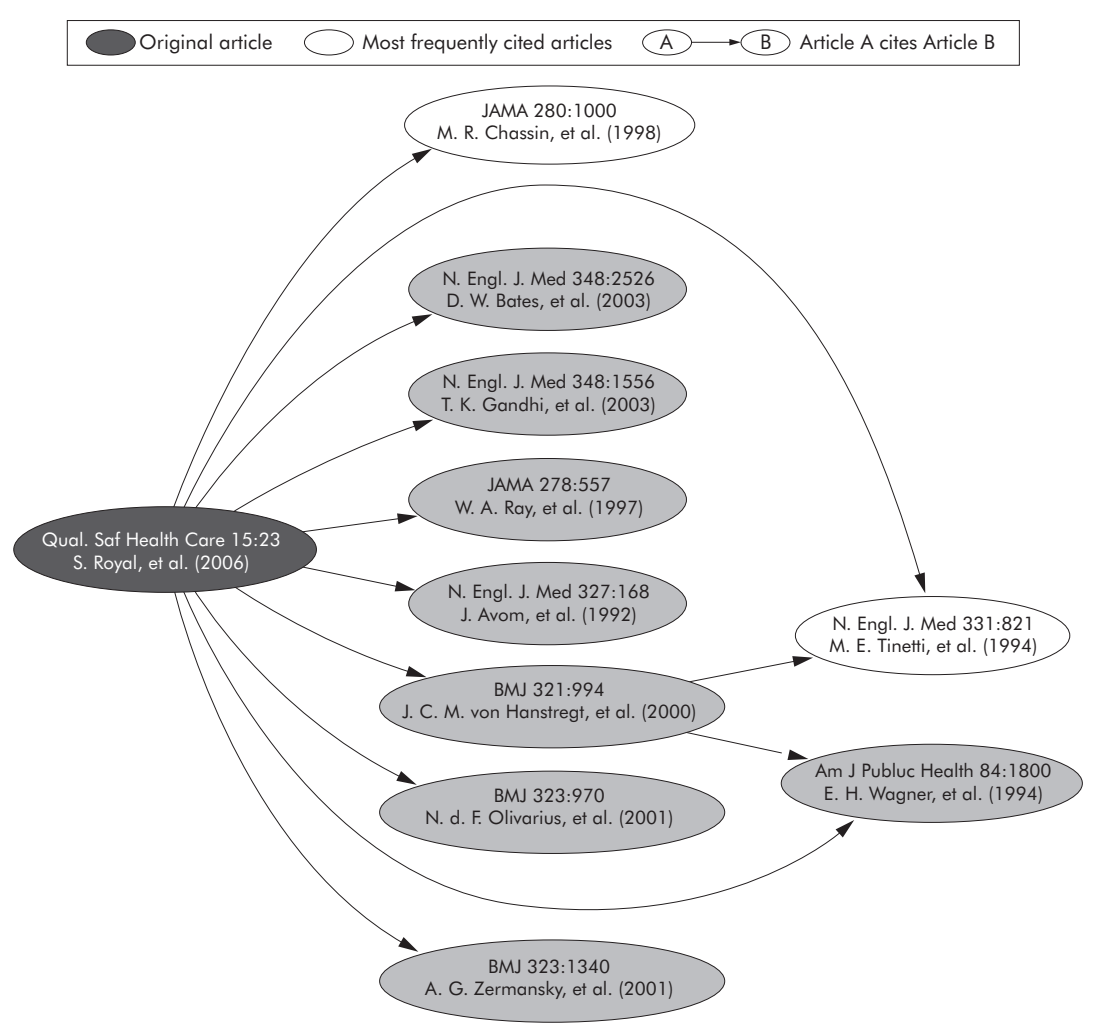

Figure 3 A citation map, the link to which is found in the contents box adjacent to the article title. This is a visual representation of how articles are interlinked.

larger version [in this window]", then click on the link marked "PowerPoint Slide for Teaching". Teaching is the obvious use for these slides, although many users will find them valuable for other presentations. But bear in mind that we cannot provide this service for illustrations for which others hold the copyright (such as cover illustrations).

Our newest feature is "Folders", which allows you to send articles to a "file drawer" for later use. To do this,

click on the link marked "Add article to my folders" in the contents box adjacent to that article. You can then file your favourite articles and searches so that you can come back to them when you wish. For those who are more organised, you can add, delete, or rename folders; move articles around between folders and copy them into more than one; and save searches in folders to use later when further studies have been published (the relevant link "Save this search to my folders" appears at the top of the search results page).

This feature is free but will require that you register so we can set up your file drawer for you. Each user has to register for a username and password before setting up folders because each person's selection of articles and searches will be unique. This single username and password will allow users to store and manage in one place articles published in any BMJ journal. ${ }^{6}$

\section{FURTHER READING}

We've recently added a PowerPoint presentation to the site that you can download. It contains all the above information as well as explaining a myriad of other features available online. Take a look at www.qshc.com/ misc/clickguide.ppt. There's a new page dedicated to helping you get the most from the site, covering technical tips and help topics (www.qshc.com/misc/ tips.dtl). There are also articles similar to this one that will help you use QSHC to your advantage. ${ }^{78}$

Qual Saf Health Care 2006;15:226-227. doi: 10.1136/qshc.2006.018804

Correspondence to: D Mitchell, BMJ Publishing Group, BMA House, Tavistock Square, London WCIH 9JR, UK; dmitchell@bmigroup.com

\section{REFERENCES}

1 Grossnickle J, Board T, Pickens B, et al. RSSCrossing into the mainstream. Yahoo, 2005.

2 Blogspace.com. http://blogspace.com/rss/

readers (accessed 29 March 2006).

3 http://highwire.stanford.edu.

4 www.crossref.org/.

5 www.ncbi.nlm.nih.gov/entrez/query.fcgi

6 www.bmijournals.com.

7 Delamothe T. Series, PowerPoint slides, and folders now available on bmj.com. BMJ 2005;331:650.

8 Delamothe T. Three new initiatives involving bmi.com. BMJ 2002;324:559-60 